\title{
The $\mathrm{H}_{2} \mathrm{O}-\mathrm{O}_{2}$ water vapour complex in the Earth's atmosphere
}

\author{
Y. Kasai ${ }^{1}$, E. Dupuy ${ }^{1}$, R. Saito ${ }^{1, *}$, K. Hashimoto ${ }^{2}$, A. Sabu ${ }^{2}$, S. Kondo $^{2}$, Y. Sumiyoshi ${ }^{3}{ }^{* *}$, and Y. Endo ${ }^{3}$ \\ ${ }^{1}$ National Institute of Information and Communications Technology, Nukui-kita, Koganei, Tokyo, 184-8795, Japan \\ ${ }^{2}$ Department of Chemistry, Tokyo Metropolitan University, Hachioji, Tokyo, 192-0397, Japan \\ ${ }^{3}$ Department of Basic Science, Graduate School of Arts and Sciences, The University of Tokyo, Komaba, Meguro-ku,Tokyo \\ 153-8902, Japan \\ *present address: Japan Agency for Marine-Earth Science and Technology (JAMSTEC) Showa-machi, Kanazawa-ku, \\ Yokohama-city, Kanagawa, 236-0001, Japan \\ ${ }^{* * *}$ present address: Department of Chemistry and Chemical Biology, Graduate School of Engineering, Gunma University,4-2 \\ Aramaki, Maebashi, Gunma 371-8510, Japan
}

Received: 5 January 2011 - Published in Atmos. Chem. Phys. Discuss.: 28 March 2011

Revised: 1 July 2011 - Accepted: 27 July 2011 - Published: 23 August 2011

\begin{abstract}
Until recently, abundance estimates for bound molecular complexes have been affected by uncertainties of a factor 10-100. This is due to the difficulty of accurately obtaining the equilibrium constant, either from laboratory experiments or by statistical thermodynamic calculations. In this paper, we firstly present laboratory experiments that we performed in order to determine the molecular structure of $\mathrm{H}_{2} \mathrm{O}-\mathrm{O}_{2}$. We also derive global abundance estimates for $\mathrm{H}_{2} \mathrm{O}-\mathrm{O}_{2}$ in the Earth's atmosphere. The equilibrium constant $K_{\mathrm{p}}$ evaluated using the "anharmonic oscillator approach" (AHOA) (Sabu et al., 2005) was employed: the AHOA explains well the structure of the complex obtained by the present experiment. The $K_{\mathrm{p}}$ calculated by this method shows a realistic temperature dependence. We used this $K_{\mathrm{p}}$ to derive global abundance estimates for $\mathrm{H}_{2} \mathrm{O}-\mathrm{O}_{2}$ in the Earth's atmosphere. The distribution of $\mathrm{H}_{2} \mathrm{O}-\mathrm{O}_{2}$ follows that of water vapour in the troposphere and seems inversely proportional to temperature in the lower stratosphere. Preliminary estimates at the surface show amount of $\mathrm{H}_{2} \mathrm{O}-\mathrm{O}_{2}$ is comparable to $\mathrm{CO}$ or $\mathrm{N}_{2} \mathrm{O}$, ranking water vapour complexes among the ten most abundant species in the boundary layer.
\end{abstract}

Correspondence to: Y. Kasai

(ykasai@nict.go.jp)

\section{Introduction}

Molecular complexes in the Earth's atmosphere are of two types: collisional, such as the oxygen dimer $\mathrm{O}_{2} \cdot \mathrm{O}_{2}$, or bound - van der Waals complexes - like the water vapour dimer $\mathrm{H}_{2} \mathrm{O}-\mathrm{H}_{2} \mathrm{O}$. In both cases, we can assume that they are at equilibrium with their parent molecules in the atmosphere. Their formation and loss processes can then be expressed as a reaction of the type $[\mathrm{A}]+[\mathrm{B}] \rightleftharpoons[\mathrm{A}-\mathrm{B}]$, with an equilibrium constant usually noted $K_{\mathrm{p}}$.

Collisional complexes have a short atmospheric lifetime, of the order of a few picoseconds, and a broad spectrum for absorption of solar radiation. They can be observed in the UV/Visible spectral range and have already been measured by satellite-borne instruments. These measurements are often used, for example, to obtain cloud top heights. The abundance of collision complexes depends on the partial pressure of the parent molecules, such as $\mathrm{O}_{2}, \mathrm{H}_{2} \mathrm{O}$ or $\mathrm{N}_{2}$, and on the temperature. Their atmospheric abundance and variations are quite well known.

On the other hand, there have been no reports of unambiguous detection of bound complexes in the atmosphere so far. In the past 2-3 decades, numerous laboratory and theoretical studies of bound complexes have been published (e.g., Calo and Narcisi, 1980; Tao et al., 1996; Paul et al., 1997; Svishchev and Boyd, 1998; Aloisio and Francisco, 2000; Vaida et al., 2001; Headrick and Vaida, 2001; Robinson and Kjaergaard, 2003; Paynter et al., 2009).

Published by Copernicus Publications on behalf of the European Geosciences Union. 
Theoretically, it should be possible to evaluate the atmospheric abundance of bound molecular complexes using the equilibrium constant $K_{\mathrm{p}}$. But estimating $K_{\mathrm{p}}$ is not a trivial task, either by laboratory experiments or statistical thermodynamic calculations, and both estimations are still affected by large uncertainties. Knowing the molecular structure of the complex is also a major issue in estimating the $K_{\mathrm{p}}$, since the calculation requires knowledge of the partition function and of the binding energy (Vaida and Headrick, 2000).

Among the bound complexes, water vapour complexes $\left(\mathrm{H}_{2} \mathrm{O}-\mathrm{X}\right.$ with, e.g., $\mathrm{X}=\mathrm{H}_{2} \mathrm{O}, \mathrm{O}_{2}$ or $\left.\mathrm{N}_{2}\right)$, are expected to have a combined surface abundance at the ppmv level, as estimated by statistical thermodynamic calculations (for example, Vaida et al., 2001). This represents ten times the amount of $\mathrm{CO}$ or $\mathrm{N}_{2} \mathrm{O}$ and would place hydrated complexes among the ten most abundant molecular compounds at ground level. More accurate knowledge of the equilibrium constant is thus of primary importance to assess their atmospheric role.

We succeeded in determining the structure of the $\mathrm{H}_{2} \mathrm{O}-\mathrm{O}_{2}$ complex by Fourier-transform microwave (FTMW) spectroscopy in the laboratory. The experimental structure and rotational constant are in good agreement with the theoretical results with the anharmonic oscillator approach (AHOA) by us (Sabu et al., 2005). The equilibrium constant, $K_{\mathrm{p}}$, evaluated by the AHOA (Sabu et al., 2005) was used to estimate the atmospheric abundance of $\mathrm{H}_{2} \mathrm{O}-\mathrm{O}_{2}$.

\section{Determination of the molecular structure of the $\mathrm{H}_{2} \mathrm{O}-\mathrm{O}_{2}$ complex}

\subsection{Laboratory experiment}

We generated and observed the $\mathrm{H}_{2} \mathrm{O}-\mathrm{O}_{2}$ spectrum using a pulsed nozzle (PN) Fourier-transform microwave (FTMW) spectrometer. A detailed description of the PN-FTMW spectrometer used in this study was presented in an earlier report (Ohshima and Endo, 1992). In short, the gas mixture of $\mathrm{H}_{2} \mathrm{O}$ and $\mathrm{O}_{2}$ in a concentration of $0.4 \%$ and $0.2 \%$, respectively, diluted in Ar was expanded into a Fabry-Perot cavity at a stagnation pressure of $3039 \mathrm{hPa}(3 \mathrm{~atm})$ through a solenoid valve and adiabatically cooled to a few Kelvin during supersonic expansion. The pressure was approximately $5 \times 10^{-5}$ torr inside the chamber. The frequency region of the measurement was from $8 \mathrm{GHz}$ to $30 \mathrm{GHz}$ with a resolution of $4 \mathrm{kHz}$. The signals were integrated from a hundred to a few thousand pulses to achieve adequate signal-to-noise ratio. We confirmed that the observed transitions belonged to $\mathrm{H}_{2} \mathrm{O}-\mathrm{O}_{2}$ by verifying the following conditions:

1. When a sample without $\mathrm{O}_{2}$ was used in the gas mixture, the signals disappeared. Similarly, without $\mathrm{H}_{2} \mathrm{O}$ in the gas mixture, no spectral signature was observed.

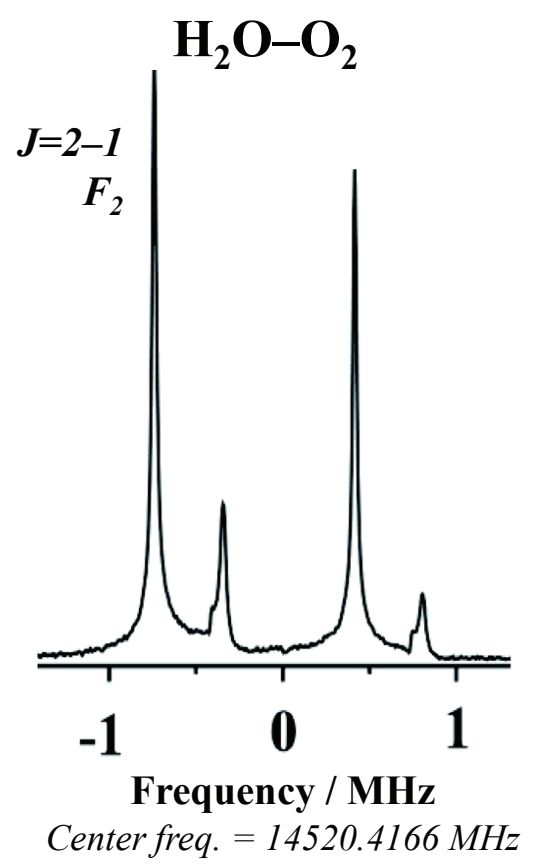

Fig. 1. Example of spectra acquired with the PN-FTMW around 14520.4 MHz, attributed to the van der Waals complex $\mathrm{H}_{2} \mathrm{O}-\mathrm{O}_{2}$.

2. Paramagnetic behavior due to the oxygen molecule. By applying a magnetic field, we confirmed that the lines were due to a paramagnetic species.

3. Magnetic hyperfine structure due to the presence of two non-zero nuclear spins with $I=1$. The magnetic hyperfine structure was observed with a relatively small $(<\mathrm{MHz})$ splitting in each of the observed rotational transitions. This is considered to be due to water vapour, since $I=1$ is the composite angular momentum of the two equivalent proton spins in the water molecule. The water molecule has a large amplitude motion with respect to the $\mathrm{C}_{2}$ axis and the average structure is $\mathrm{C}_{2 \mathrm{v}}$, as explained in Sabu et al. $(2004,2005)$.

A total of 21 transitions including fine and hyperfine splittings were successfully observed in the $8-30 \mathrm{GHz}$ region. They are listed in Table 1, which also gives the less numerous $\mathrm{D}_{2} \mathrm{O}-\mathrm{O}_{2}$ observed transitions. An example spectrum for $\mathrm{H}_{2} \mathrm{O}-\mathrm{O}_{2}$ around $14520 \mathrm{MHz}$ is shown in Fig. 1.

\subsection{Spectral analysis}

We succeeded in analyzing the spectrum of the $\mathrm{H}_{2} \mathrm{O}-\mathrm{O}_{2}$ complex using the Hamiltonian of a ${ }^{3} \Sigma$ state for Hund's case (a), since the observed transitions are assigned to the series of the $K_{a}=0$ component.

The Hamiltonian can be expressed as

$\mathbf{H}=\mathbf{H}_{\mathrm{rot}}+\mathbf{H}_{\mathrm{sr}}+\mathbf{H}_{\mathrm{ss}}$ 
Table 1. Observed transition frequencies (in $\mathrm{MHz}$ ) of $\mathrm{H}_{2} \mathrm{O}-\mathrm{O}_{2}$ (upper part) and $\mathrm{D}_{2} \mathrm{O}-\mathrm{O}_{2}$ (lower rows) and difference with the frequencies calculated using the Hamiltonian in the ${ }^{3} \Sigma$ state for Hund's case (a) and $\mathrm{K}=0 . N, J$ and $F$ represent the rotational angular momentum, the total angular momentum and the total angular momentum including nuclear spin, respectively.

\begin{tabular}{|c|c|c|c|c|c|c|c|}
\hline \multirow[b]{2}{*}{$N^{\prime}$} & \multirow[b]{2}{*}{$J^{\prime}$} & \multicolumn{2}{|c|}{ Transition } & \multirow[b]{2}{*}{$J^{\prime \prime}$} & \multirow[b]{2}{*}{$F^{\prime \prime}$} & \multirow{2}{*}{$\begin{array}{r}\text { Obs. Freq. } \\
(\mathrm{MHz})\end{array}$} & \multirow{2}{*}{$\begin{array}{r}\text { Obs.-Calc. } \\
(\mathrm{MHz})\end{array}$} \\
\hline & & $F^{\prime}$ & $N^{\prime \prime}$ & & & & \\
\hline \multicolumn{8}{|c|}{$\mathrm{H}_{2} \mathrm{O}-\mathrm{O}_{2}$} \\
\hline 2 & 2.0 & 1.0 & 1 & 1.0 & 1.0 & 14520.0732 & -.0697 \\
\hline 2 & 2.0 & 2.0 & 1 & 1.0 & 1.0 & 14520.8316 & -.0573 \\
\hline 2 & 2.0 & 3.0 & 1 & 1.0 & 2.0 & 14519.6794 & -.0905 \\
\hline 2 & 2.0 & 1.0 & 1 & 1.0 & .0 & 14521.2234 & -.0385 \\
\hline 2 & 2.0 & 2.0 & 1 & 1.0 & 2.0 & 14518.5576 & -.0934 \\
\hline 2 & 2.0 & 2.0 & 1 & 2.0 & 1.0 & 17839.8957 & .0222 \\
\hline 2 & 2.0 & 3.0 & 1 & 2.0 & 2.0 & 17839.5000 & .0785 \\
\hline 2 & 2.0 & 4.0 & 1 & 2.0 & 3.0 & 17838.9337 & -.0676 \\
\hline 3 & 3.0 & 2.0 & 2 & 2.0 & 2.0 & 21755.9556 & .0793 \\
\hline 3 & 3.0 & 3.0 & 2 & 2.0 & 3.0 & 21755.3957 & .0789 \\
\hline 3 & 3.0 & 4.0 & 2 & 2.0 & 3.0 & 21756.1194 & .0567 \\
\hline 3 & 3.0 & 2.0 & 2 & 2.0 & 1.0 & 21756.7120 & .0898 \\
\hline 3 & 3.0 & 3.0 & 2 & 2.0 & 2.0 & 21756.5144 & .0787 \\
\hline 3 & 4.0 & 3.0 & 2 & 3.0 & 2.0 & 24090.4179 & -.0783 \\
\hline 3 & 4.0 & 4.0 & 2 & 3.0 & 3.0 & 24090.1436 & .0237 \\
\hline 3 & 4.0 & 5.0 & 2 & 3.0 & 4.0 & 24089.8048 & .0263 \\
\hline 4 & 4.0 & 3.0 & 3 & 3.0 & 2.0 & 28963.7677 & -.0162 \\
\hline 4 & 4.0 & 4.0 & 3 & 3.0 & 3.0 & 28963.6508 & -.0212 \\
\hline 4 & 4.0 & 5.0 & 3 & 3.0 & 4.0 & 28963.4508 & -.0347 \\
\hline 4 & 4.0 & 3.0 & 3 & 3.0 & 3.0 & 28963.2342 & .0353 \\
\hline 4 & 4.0 & 4.0 & 3 & 3.0 & 4.0 & 28962.9613 & .0098 \\
\hline \multicolumn{8}{|c|}{$\mathrm{D}_{2} \mathrm{O}-\mathrm{O}_{2}$} \\
\hline 2 & 2.0 & 1.0 & 1 & 1.0 & 1.0 & 13419.5779 & -.0289 \\
\hline 2 & 2.0 & 2.0 & 1 & 1.0 & 1.0 & 13419.6962 & -.0331 \\
\hline 2 & 2.0 & 2.0 & 1 & 1.0 & 2.0 & 13419.3506 & -.0245 \\
\hline 2 & 2.0 & 3.0 & 1 & 1.0 & 2.0 & 13419.5144 & -.0326 \\
\hline 3 & 3.0 & 3.0 & 2 & 2.0 & 2.0 & 20111.9415 & .0765 \\
\hline 3 & 3.0 & 3.0 & 2 & 2.0 & 3.0 & 20111.7272 & .0341 \\
\hline 3 & 3.0 & 4.0 & 2 & 2.0 & 3.0 & 20111.8461 & .0415 \\
\hline 4 & 4.0 & 3.0 & 3 & 3.0 & 2.0 & 28963.7677 & .0106 \\
\hline 4 & 4.0 & 4.0 & 3 & 3.0 & 3.0 & 28963.6508 & -.0204 \\
\hline 4 & 4.0 & 5.0 & 3 & 3.0 & 4.0 & 28963.4508 & -.0299 \\
\hline
\end{tabular}

$$
=B \mathbf{N}^{2}-D \mathbf{N}^{4}+\gamma \mathbf{N} \cdot \mathbf{S}+(2 / 3) \lambda\left(3 S_{z}^{2}-\mathbf{S}^{2}\right)
$$

where $\mathbf{N}$ is the angular momentum of the rotation and $\mathbf{S}$ is the electron spin. $\gamma$ and $\lambda$ are the spin-rotation and spin-spin coupling constants, respectively.

The following hyperfine terms were included in addition to Eq. 2 due to the two hydrogens of water vapour:

$$
\mathbf{H}_{\mathrm{hfs}}=b_{F} \mathbf{I} \cdot \mathbf{S}+c / 3\left(I_{z} S_{z}-\mathbf{I} \cdot \mathbf{S}\right)
$$

where $b_{F}$ and $c$ represent the Fermi contact interaction and the dipole-dipole interaction constants, respectively. The calculated transition frequencies were fitted to the experimental values through a least squares fitting procedure. The molecular constants thus determined are listed in Table 2 for both

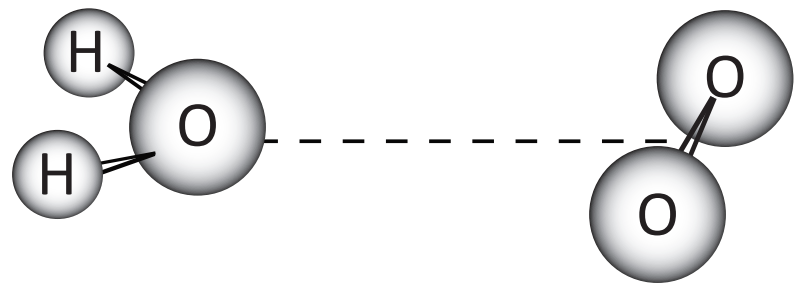

Fig. 2. Molecular structure of the van der Waals complex $\mathrm{H}_{2} \mathrm{O}-\mathrm{O}_{2}$ determined to be $\mathrm{C}_{2 \mathrm{v}}$ by PN-FT microwave spectroscopy.

Table 2. Molecular constants in $\mathrm{MHz}$ for $\mathrm{H}_{2} \mathrm{O}-\mathrm{O}_{2}$ and $\mathrm{D}_{2} \mathrm{O}-\mathrm{O}_{2}$. For the $\mathrm{D}_{2} \mathrm{O}-\mathrm{O}_{2}$ calculations, $\lambda_{0}, \lambda_{D}$ and $\gamma$ were fixed to the $\mathrm{H}_{2} \mathrm{O}-\mathrm{O}_{2}$ values (left column).

\begin{tabular}{lrrr}
\hline & & $\mathrm{H}_{2} \mathrm{O}_{-} \mathrm{O}_{2}$ & $\mathrm{D}_{2} \mathrm{O}-\mathrm{O}_{2}$ \\
\hline$B_{0}=$ & $3633.197(14)$ & $3357.211(13)$ \\
$D_{0}$ & $=$ & $0.39942(84)$ & $0.29293(49)$ \\
$\lambda_{0}=$ & $64136.0(19)$ & - \\
$\lambda_{D}=$ & $0.051673($ fixed) & - \\
$\gamma$ & $=$ & $-1997.924(49)$ & - \\
$b_{F}$ & $=$ & $-1.82(23)$ & -0.28 \\
$c$ & $=$ & $6.09(36)$ & $0.94(15)$
\end{tabular}

the $\mathrm{H}_{2} \mathrm{O}-\mathrm{O}_{2}$ and the $\mathrm{D}_{2} \mathrm{O}-\mathrm{O}_{2}$ complexes. $B_{0}$ and $D_{0}$ are the rotational constant and the centrifugal distortion constant in the vibrational ground state $(v=0)$, respectively. $\lambda_{0}$ is the spin-spin coupling constant (also for $v=0$ ), while $\lambda_{D}$ is the centrifugal distortion constant for the spin-spin coupling.

\subsection{Molecular structure of the $\mathrm{H}_{2} \mathrm{O}-\mathrm{O}_{2}$ complex}

The values of the rotational constant $B_{0}$ for $\mathrm{H}_{2} \mathrm{O}-\mathrm{O}_{2}$ and $\mathrm{D}_{2} \mathrm{O}-\mathrm{O}_{2}$ were found to be $3633.197(14) \mathrm{MHz}$ and 3357.211(13) MHz, respectively. The difference between these constants indicates a $\mathrm{C}_{2 \mathrm{v}}$ structure with the two hydrogens of the water molecule in an outer position, as shown in Fig. 2. The direction of the complex axis is perpendicular to that of the molecular oxygen axis, as indicated by the symmetry of the complex, where the electronic ground state is anti-symmetric with respect to the $\mathrm{C}_{2}$ rotation about the complex axis. These values of $B_{0}$ with the $\mathrm{C}_{2 \mathrm{v}}$ structure are consistent with the theoretical ab initio calculations of Sabu et al. (2004, 2005), but not with the $\mathrm{C}_{\mathrm{S}}$ structure of Svishchev and Boyd (1998). Details of the comparison of the rotational constants obtained in our experiment with these obtained by ab initio calculations are described in Sabu et al. (2004). Therefore, we concluded that the molecular structure of $\mathrm{H}_{2} \mathrm{O}-\mathrm{O}_{2}$ is $\mathrm{C}_{2}$ in the vibronic ground state. 


\section{Estimation of $K_{p}$}

\subsection{Determination method and previous studies}

Aside from atmospheric observations, there are two main approaches to estimate the equilibrium constant: direct measurement in the laboratory or estimation with statistical thermodynamics.

In the statistical thermodynamics approach, $K_{\mathrm{p}}$ is calculated using Gibb's free energy $\Delta G$ from the equation $K_{p} \cdot P=\exp (-\Delta G / R T)$, where $R$ is the universal gas constant and $T$ the temperature. $\Delta G$ is calculated as $\Delta G=$ $\Delta H-T \Delta S$. Here, $\Delta H$ and $\Delta S$ represent the change in enthalpy and in entropy, respectively, for the formation of the complex at a total pressure $P$ and temperature $T$.

In the case of $\mathrm{H}_{2} \mathrm{O}-\mathrm{O}_{2}, K_{\mathrm{p}}$ depends on the temperature and on the binding energy between $\mathrm{H}_{2} \mathrm{O}$ and $\mathrm{O}_{2}$ through $\Delta H$, while $\Delta S$ uses the partition functions obtained from the rotational, vibrational, and electronic energy level structures of $\mathrm{H}_{2} \mathrm{O}-\mathrm{O}_{2}, \mathrm{H}_{2} \mathrm{O}$, and $\mathrm{O}_{2}$. A more detailed description is given elsewhere (Vaida and Headrick, 2000; Kjaergaard et al., 2002; Sabu et al., 2005).

\section{2 $\quad K_{\mathrm{p}}$ obtained with the anharmonic approach}

The studies of Vaida and Headrick (2000) and Kjaergaard et al. (2002) both used the harmonic oscillator approximation to calculate the partition functions needed to estimate $K_{\mathrm{p}}$. Alternately, Sabu et al. (2005) calculated the partition function, and thus $K_{\mathrm{p}}$, using another approach. They carefully examined all inter- and intra-molecular vibrations and evaluated the anharmonic levels below the dissociation limit (Sabu et al., 2005).

These estimated $K_{\mathrm{p}}$ values are plotted against temperature in Fig. 3. From this figure, it is easy to notice the limitations of the harmonic oscillator approximation in estimating the equilibrium constant. The $K_{\mathrm{p}}$ of Vaida and Headrick (2000) shows a peculiar increase, almost linearly proportional to temperature. The $K_{\mathrm{p}}$ values of Kjaergaard et al. (2002) have a minimum around $225 \mathrm{~K}$ and increase at high temperatures, indicating no dissociation of the complex. In both cases the behaviour of $K_{\mathrm{p}}$ is not compatible with the estimated structure of the $\mathrm{H}_{2} \mathrm{O}-\mathrm{O}_{2}$ complex.

In sharp contrast, only the anharmonic estimate of $K_{\mathrm{p}}$ monotonically (exponentially) deacreases with increasing temperature. The absolute values of $K_{\mathrm{p}}$ are much smaller than the other estimates, because of the low binding energy and the small number of bound states. On the basis of $K_{\mathrm{p}}$ decreasing correctly with temperature, the inferred volume mixing ratios of the $\mathrm{H}_{2} \mathrm{O}-\mathrm{O}_{2}$ complex at atmospheric temperatures are 1-2 orders of magnitude lower than those calculated by the harmonic approximation (Sabu et al., 2005).

It is worth emphasizing that only the calculations of $K_{\mathrm{p}}$ from Sabu et al. (2005) show a correct decrease with increas-

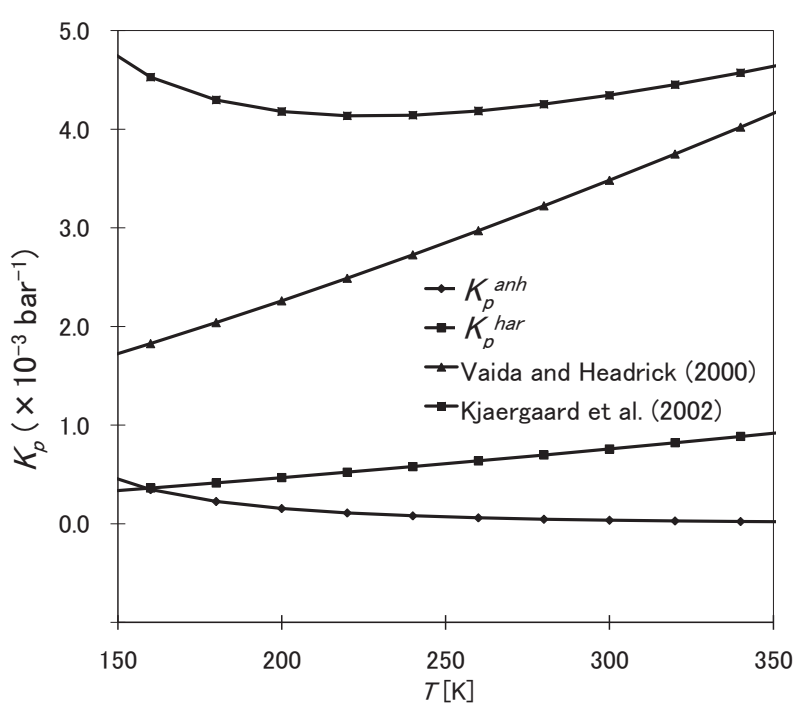

Fig. 3. Calculated equilibrium constant $K_{\mathrm{p}}$ for $\mathrm{H}_{2} \mathrm{O}-\mathrm{O}_{2}$ using different methods (after Sabu et al., 2005) . The uppermost line (small square symbols) shows the results of Kjaergaard et al. (2002) and the triangle symbols those of Vaida and Headrick (2000). The lines with lozenge and big square symbols are the results of the anharmonic and harmonic calculations of Sabu et al. (2005), respectively.

ing temperature. Therefore, this set of values is the best estimate of $K_{\mathrm{p}}$ for $\mathrm{H}_{2} \mathrm{O}-\mathrm{O}_{2}$ among the data currently available.

\section{Atmospheric abundance of the $\mathrm{H}_{2} \mathrm{O}-\mathrm{O}_{2}$ complex}

The atmospheric abundance of the $\mathrm{H}_{2} \mathrm{O}-\mathrm{O}_{2}$ complex is represented by the equilibrium equation given below:

$\left[\mathrm{H}_{2} \mathrm{O}\right]+\left[\mathrm{O}_{2}\right]+[\mathrm{M}] \rightleftharpoons\left[\mathrm{H}_{2} \mathrm{O}-\mathrm{O}_{2}\right]+[\mathrm{M}]$.

From Eq. (4) we can infer the atmospheric partial pressure of the complex:

$\left(\frac{P_{\mathrm{H}_{2} \mathrm{O}-\mathrm{O}_{2}}}{P}\right)=K_{\mathrm{p}} \cdot P \cdot\left(\frac{P_{\mathrm{H}_{2} \mathrm{O}}}{P}\right)\left(\frac{P_{\mathrm{O}_{2}}}{P}\right)$,

where $\left(P_{\mathrm{H}_{2} \mathrm{O}-\mathrm{O}_{2}} / P\right),\left(P_{\mathrm{H}_{2} \mathrm{O}} / P\right)$, and $\left(P_{\mathrm{O}_{2}} / P\right)$ are the partial pressures of the $\mathrm{H}_{2} \mathrm{O}-\mathrm{O}_{2}$ complex, $\mathrm{H}_{2} \mathrm{O}$ and $\mathrm{O}_{2}$, respectively, for a given atmospheric pressure $P$. The partial pressure for a given molecule is related to its volume mixing ratio $(\mathrm{VMR})$ by $\mathrm{PP}=\mathrm{VMR} \times P_{\text {dry air }} . K_{\mathrm{p}}$ is the equilibrium constant. The abundance of $\mathrm{H}_{2} \mathrm{O}-\mathrm{O}_{2}$ is proportional to $K_{\mathrm{p}}$ and to the abundances of water vapour and of molecular oxygen (and inversely proportional to $P$ ).

\subsection{Calculation setup}

The $\mathrm{H}_{2} \mathrm{O}-\mathrm{O}_{2}$ VMR distribution was derived from the partial pressure calculated using Eq. (5). We used the $K_{\mathrm{p}}$ values calculated by Sabu et al. (2005) with the anharmonic oscillator 

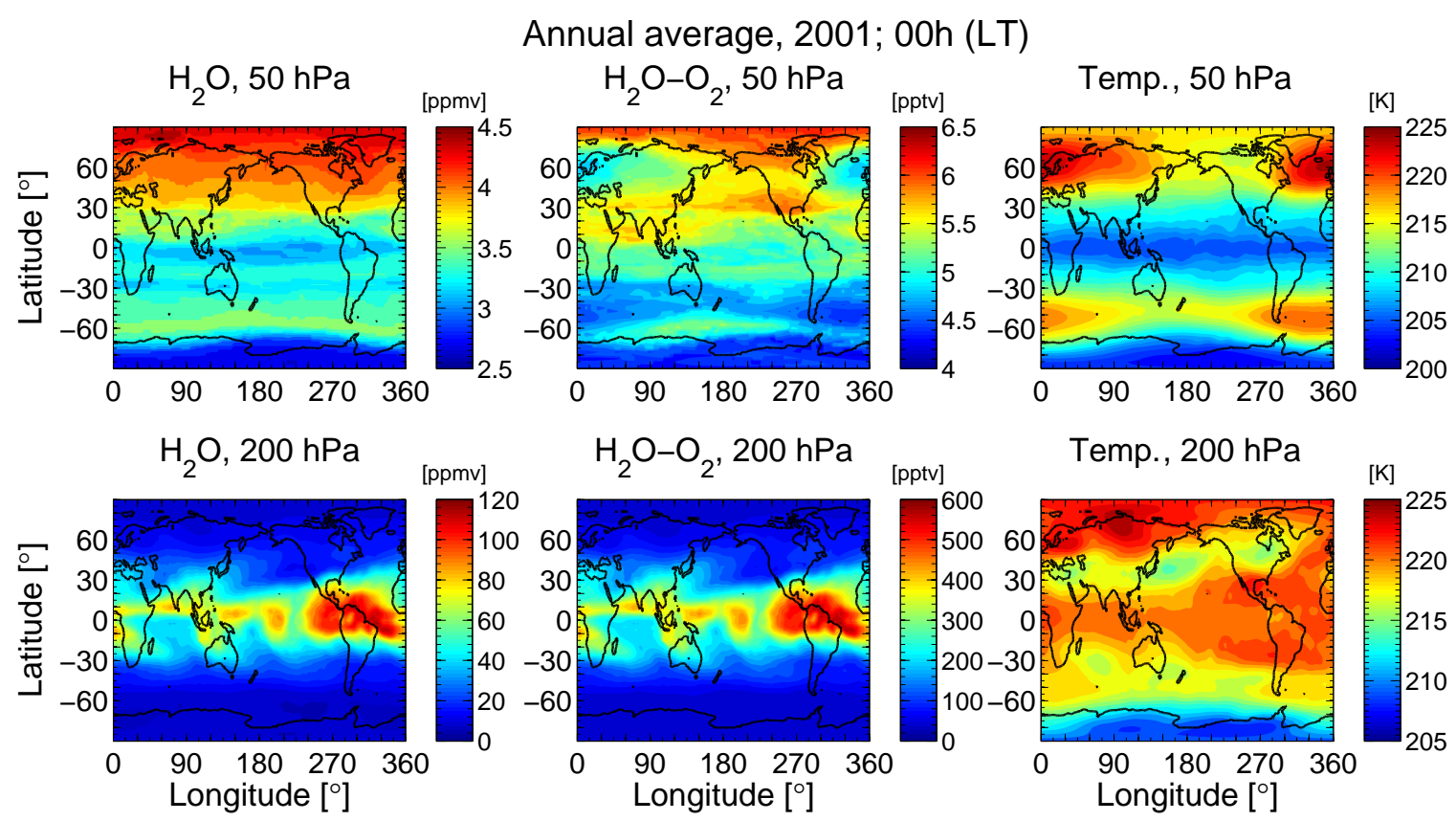

Temp., $200 \mathrm{hPa}$

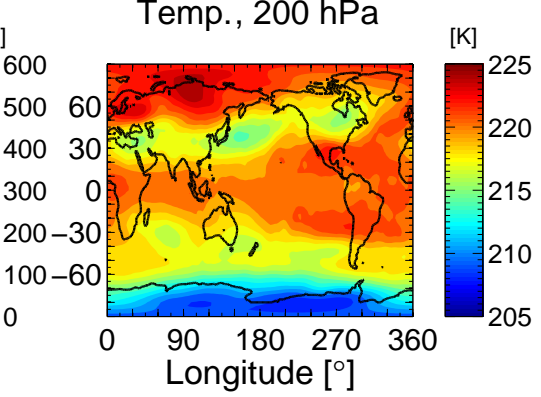

Fig. 4. Global distribution in latitude/longitude of the $\mathrm{H}_{2} \mathrm{O}$ (left) and $\mathrm{H}_{2} \mathrm{O}-\mathrm{O}_{2}$ (middle) VMRs and of the atmospheric temperature (right). The annual averages for 2001 at $0 \mathrm{~h}$ (Local Time) are shown at 50 (top) and 200 (bottom) $\mathrm{hPa}(\sim 21$ and $12 \mathrm{~km}$, respectively). The temperature data and the specific humidity field used to derive the $\mathrm{H}_{2} \mathrm{O}$ VMR are taken from the ERA-40 reanalysis of the ECMWF data (see text). The VMR of the $\mathrm{H}_{2} \mathrm{O}-\mathrm{O}_{2}$ complex is calculated using the equilibrium equation (Eq. 5), with the $K_{\mathrm{p}}$ values derived from Sabu et al. (2005). The horizontal grid sampling is $2.5^{\circ} \times 2.5^{\circ}$.

approximation, tabulated as a function of temperature from $150 \mathrm{~K}$ to $350 \mathrm{~K}$ with a step of $5 \mathrm{~K}$.

The partial pressure of $\mathrm{O}_{2}$ was set to a constant value at all levels, equal to $20.946 \%$ of the dry air pressure. The temperature, pressure and specific humidity were taken from the European Center for Medium-range Weather Forecast (ECMWF) ERA-40 reanalysis dataset (Uppala et al., 2005). The ERA-40 data fields, sampled on 23 pressure levels from 1000 to $1 \mathrm{hPa}$, are provided as monthly averages at $0 \mathrm{~h}, 6 \mathrm{~h}$, $12 \mathrm{~h}$ and $18 \mathrm{~h}$ (Local Time) on a latitude/longitude grid with a $2.5^{\circ} \times 2.5^{\circ}$ horizontal resolution.

For this study we calculated an annual average for 2001 at 00:00 h LT, sufficient to assess the usefulness of the $K_{\mathrm{p}}$ measurements for atmospheric applications. Figure 4 shows the inferred global distribution of $\mathrm{H}_{2} \mathrm{O}-\mathrm{O}_{2}$ (middle column) for the 2001 average, at 200 and $50 \mathrm{hPa}$ (about 12 and $21 \mathrm{~km}$, respectively). These height levels were chosen to illustrate the difference between the tropospheric $(200 \mathrm{hPa})$ and stratospheric $(50 \mathrm{hPa})$ distributions of the molecular complex. For comparison the distribution of the water vapour VMR and of the atmospheric temperature are given at the same heights.

\subsection{Distribution of $\mathrm{H}_{2} \mathrm{O}-\mathrm{O}_{2}$}

From Fig. 4 it is possible to get some qualitative understanding of the distribution of the $\mathrm{H}_{2} \mathrm{O}-\mathrm{O}_{2}$ complex. Two different behaviours can be identified. In the upper troposphere (represented by the $200 \mathrm{hPa}$ level, lower row) the VMR of the complex is strongly correlated to the water vapour amount. The $\mathrm{H}_{2} \mathrm{O}-\mathrm{O}_{2}$ VMR is largest in the equatorial region and small in the mid- and high latitudes of both hemispheres. This corresponds very well to the water vapour distribution, whereas the temperature is highest at Northern high latitudes.

Above the tropopause ( $50 \mathrm{hPa}$ level, upper row), the situation is different. Temperature has a marked minimum at the Equator, where there is also little $\mathrm{H}_{2} \mathrm{O}$ or $\mathrm{H}_{2} \mathrm{O}-\mathrm{O}_{2}$. Conversely, at higher latitudes (from $30-40^{\circ}$ in both hemispheres), there is an obvious correlation between high temperatures and low levels of $\mathrm{H}_{2} \mathrm{O}-\mathrm{O}_{2}$ : the VMR of the molecular complex seems inversely proportional to the atmospheric temperature, while the water vapour distribution is rather homogeneous with large values in the Northern Hemisphere and small values in the Southern Hemisphere.

The inferred abundance of $\mathrm{H}_{2} \mathrm{O}-\mathrm{O}_{2}$ in the Earth's boundary layer $(1000 \mathrm{hPa}$, not shown) ranges from 1 to about $250 \mathrm{ppbv}$. This is comparable to $\mathrm{CO}(\sim 200 \mathrm{ppbv})$ or to $\mathrm{N}_{2} \mathrm{O}$ $(\sim 300 \mathrm{ppbv})$. Estimating the abundance of water vapour complexes is therefore important for tropospheric chemistry. 


\section{Summary}

We performed laboratory spectroscopic experiments for the $\mathrm{H}_{2} \mathrm{O}-\mathrm{O}_{2}$ complex and determined its molecular structure. The result differs from the potential minimum-structures but agrees well with that calculated by the anharmonic oscillator approach, which increases our confidence in the quality of the $K_{\mathrm{p}}$ estimated by the same method. Using these highquality values of $K_{\mathrm{p}}$ allowed us to provide a first (theoretical) estimate of the atmospheric distribution of $\mathrm{H}_{2} \mathrm{O}-\mathrm{O}_{2}$. The inferred abundance of $\mathrm{H}_{2} \mathrm{O}-\mathrm{O}_{2}$ at the Earth's surface is at the sub-ppmv level. This is comparable to the surface concentrations of $\mathrm{CO}$ or $\mathrm{N}_{2} \mathrm{O}$ and shows that knowledge of the abundance of water vapour complexes is undeniably important to further our understanding of tropospheric processes.

Acknowledgements. This work was supported in part by grants-inaid from the Japanese Society for the Promotion of Science (JSPS Grant-in-Aid for Scientific Research C, no. 20550019, and Grantin-Aid for Scientific Research on Priority Areas, no.13127102). Y. $\mathrm{K}$ is grateful for supports and encouragements from N. Washida (NIES; Kyoto Unievrsity), and T. Imamura (NIES).

Edited by: R. Volkamer

\section{References}

Aloisio, S. and Francisco, J. S.: Radical-water complexes in Earth's atmosphere, Acc. Chem Res., 33, 825-830, doi:10.1021/ar000097u, 2000.

Calo, J. M. and Narcisi, R. S.: Van Der Waals molecules - Possible roles in the atmosphere, Geophys. Res. Lett., 7, 289-292, doi:10.1029/GL007i005p00289, 1980.

Headrick, J. E. and Vaida, V.: Significance of water complexes in the atmosphere, Phys. Chem. Earth, 26, 479-486, doi:10.1016/S1464-1917(01)00035-6, 2001.

Kjaergaard, H. G., Low, G. R., Robinson, T. W., and Howard, D. L.: Calculated $\mathrm{OH}-\mathrm{Stretching}$ vibrational transitions in the waternitrogen and water-oxygen complexes, J. Phys. Chem. A, 106, 8955-8962, doi:10.1021/jp020542y, 2002.

Ohshima, Y. and Endo, Y.: Structure of C3S studied by pulsed-discharge-nozzle Fourier-transform microwave spectroscopy, J. Molec. Spectrosc., 153, 627-634, doi:10.1016/00222852(92)90498-D, 1992.
Paul, J. B., Collier, C. P., Saykally, R. J., Scherer, J. J., and O'Keefe, A.: Direct measurement of water cluster concentrations by infrared cavity ringdown laser absorption spectroscopy, J. Phys. Chem. A, 101, 5211-5214, 1997.

Paynter, D. J., Ptashnik, I. V., Shine, K. P., Smith, K. M., McPheat, R., and Williams, R. G.: Laboratory measurements of the water vapor continuum in the $1200-8000 \mathrm{~cm}^{-1}$ region between $293 \mathrm{~K}$ and $351 \mathrm{~K}$, J. Geophys. Res., 114, D21 301, doi:10.1029/2008JD011355, 2009.

Robinson, T. W. and Kjaergaard, H. G.: High level $a b$ initio studies of the low-lying excited states in the $\mathrm{H}_{2} \mathrm{O}-\mathrm{O}_{2}$ complex, J. Chem. Phys., 119, 3717-3720, doi:10.1063/1.1591733, 2003.

Sabu, A., Kondo, S., Miura, N., and Hashimoto, K.: Potential energy surface and intermolecular vibrations of $\mathrm{O}_{2}-\mathrm{H}_{2} \mathrm{O}$, Chem. Phys. Lett., 391, 101-105, doi:10.1016/j.cplett.2004.04.071, 2004.

Sabu, A., Kondo, S., Saito, R., Kasai, Y., and Hashimoto, K.: Theoretical study of $\mathrm{O}_{2}-\mathrm{H}_{2} \mathrm{O}$ : Potential energy surface, molecular vibrations, and equilibrium constant at atmospheric temperatures, J. Phys. Chem. A, 109, 1836-1842, doi:10.1021/jp0482518, 2005.

Svishchev, I. M. and Boyd, R. J.: Van Der Waals complexes of water with oxygen and nitrogen: Infrared spectra and atmospheric implications, J. Phys. Chem. A, 102, 7294-7296, doi:10.1021/jp981166d, 1998.

Tao, F.-M., Higgins, K., Klemperer, W., and Nelson, D. D.: Structure, binding energy, and equilibrium constant of the nitric acid-water complex, Geophys. Res. Lett., 23, 1797-1800, doi:10.1029/96GL00947, 1996.

Uppala, S. M., Kållberg, P. W., Simmons, A. J., Andrae, U., Bechtold, V. D. C., Fiorino, M., Gibson, J. K., Haseler, J., Hernandez, A., Kelly, G. A., Li, X., Onogi, K., Saarinen, S., Sokka, N., Allan, R. P., Andersson, E., Arpe, K., Balmaseda, M. A., Beljaars, A. C. M., Berg, L. V. D., Bidlot, J., Bormann, N., Caires, S., Chevallier, F., Dethof, A., Dragosavac, M., Fisher, M., Fuentes, M., Hagemann, S., Hólm, E., Hoskins, B. J., Isaksen, L., Janssen, P. A. E. M., Jenne, R., McNally, A. P., Mahfouf, J.-F., Morcrette, J.-J., Rayner, N. A., Saunders, R. W., Simon, P., Sterl, A., Trenberth, K. E., Untch, A., Vasiljevic, D., Viterbo, P., and Woollen, J.: The ERA-40 re-analysis, Q. J. R. Meteorol. Soc., 131, 29613012, doi:10.1256/qj.04.176, 2005.

Vaida, V. and Headrick, J. E.: Physicochemical properties of hydrated complexes in the Earth's atmosphere, J. Phys. Chem. A, 104, 5401-5412, doi:10.1021/jp000115p, 2000.

Vaida, V., Daniel, J. S., Kjaergaard, H. G., Goss, L. M., and Tuck, A. F.: Atmospheric absorption of near infrared and visible solar radiation by the hydrogen bonded water dimer, Q. J. R. Meteorol. Soc., 127, 1627-1643, doi:10.1002/qj.49712757509, 2001. 